Review

\title{
In Silico-Enhanced Treatment and Rehabilitation Planning for Patients with Musculoskeletal Disorders: Can Musculoskeletal Modelling and Dynamic Simulations Really Impact Current Clinical Practice?
}

\author{
Bryce A Killen * ${ }^{(\mathbb{C}}$, Antoine Falisse ${ }^{(}$, Friedl De Groote $\left.{ }^{(}\right)$and Ilse Jonkers $₫$ \\ Human Movement Biomechanics Research Group, Department of Movement Sciences, KU Leuven, \\ 3001 Leuven, Belgium; antoine.falisse@kuleuven.be (A.F.); friedl.degroote@kuleuven.be (F.D.G.); \\ ilse.jonkers@kuleuven.be (I.J.) \\ * Correspondence: bryce.killen@kuleuven.be
}

Received: 31 August 2020; Accepted: 13 October 2020; Published: 16 October 2020

\begin{abstract}
Over the past decades, the use of computational physics-based models representative of the musculoskeletal (MSK) system has become increasingly popular in many fields of clinically driven research, locomotor rehabilitation in particular. These models have been applied to various functional impairments given their ability to estimate parameters which cannot be readily measured in vivo but are of interest to clinicians. The use of MSK modelling and simulations allows analysis of relevant MSK biomarkers such as muscle and joint contact loading at a number of different stages in the clinical treatment pathway in order to benefit patient functional outcome. Applications of these methods include optimisation of rehabilitation programs, patient stratification, disease characterisation, surgical pre-planning, and assistive device and exoskeleton design and optimisation. This review provides an overview of current approaches, the components of standard MSK models, applications, limitations, and assumptions of these modelling and simulation methods, and finally proposes a future direction.
\end{abstract}

Keywords: musculoskeletal modelling; musculoskeletal simulations; clinical research; rehabilitation; biomechanics

\section{Introduction}

The rise of high-powered computing has revolutionised both clinical and research fields, allowing the processing and collection of large amounts of data. In addition, new and complex methodologies have and continue to be developed addressing clinically relevant questions. These developments are present in many fields including cell biology, oncology, and drug development to name a few. One other field which has greatly benefitted is that of human movement biomechanics. The emergence of computational musculoskeletal (MSK) models in the past 30+ years has allowed great progress to be made in the field. MSK models present a mathematical description of the human musculoskeletal system (See Section 2 for detailed explanation), in terms of its segments, joints, and muscles as well as functional components including joint movement (i.e., kinematics) as well as muscle geometry and force-generating capacity.

The use of MSK models within both the research (considering all research fields, including sports, clinical, etc.) and clinical fields has and continues to rise (Figure 1). These physics-based modelling and simulation workflows provide an integrative platform that allows users to combine traditionally collected experimental data (i.e., three dimensional (3D) motion capture) with information on 3D structure and function of the MSK system (i.e., MSK model) allowing more advanced parameters to 
be estimated. Specific parameters which can be estimated using these methods include joint angles (i.e., kinematics) and moments (i.e., kinetics), but extend to MSK structure loading (i.e., ligament and muscle forces) and joint contact loading. Many of which cannot be estimated without the use of MSK models. In addition to studying these parameters in isolation, interactions (e.g., effect of kinematics/moments on joint contact loading) can also be investigated. These additional parameters can be applied to various MSK conditions and numerous stages of the clinical treatment pathway.

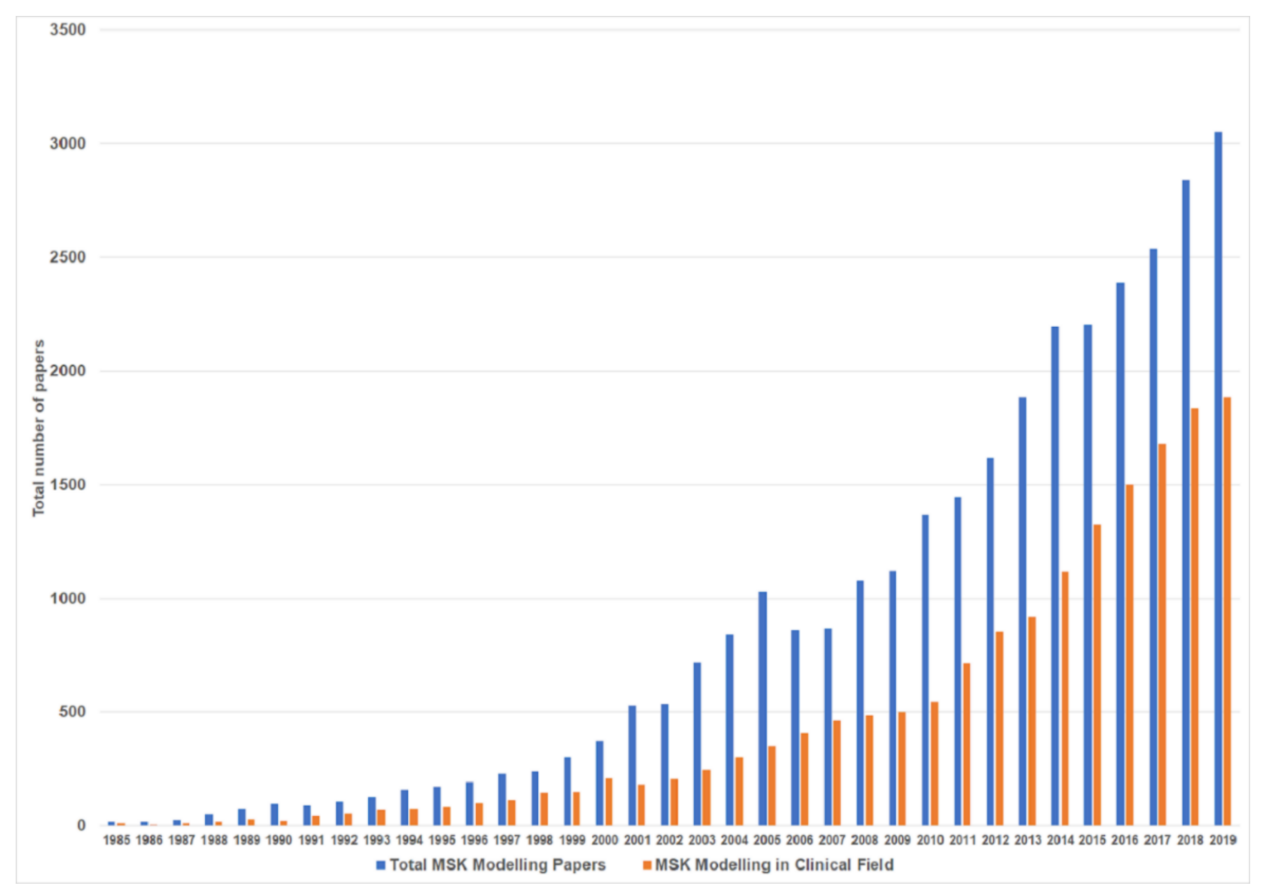

Figure 1. Total numbers of papers (blue) using musculoskeletal (MSK) modelling (Source: PubMed https://pubmed.ncbi.nlm.nih.gov/), and number of clinical science papers (orange) using MSK modelling (Source: Dimensions https://app.dimensions.ai/).

The remainder of this paper will present three sections: first, an educational component explaining MSK models (See Section 2.1) and their associated simulation methods (See Sections 2.2-2.8). The second section provides examples of specific clinical applications where MSK models have been and are currently being introduced to enhance treatment. Specifically, using MSK modelling and simulations, MSK diseases and conditions can be investigated to determine disease-specific characteristics (see Section 3). Furthermore, by testing patients at multiple time points, disease-specific biomarkers can be determined which predispose patients to disease progression, giving insights into disease aetiology (see Section 3). In the context of MSK rehabilitation using MSK modelling and simulation tools, the precise load applied to MSK tissues during functional activities can be estimated and compared to loading guidelines. Physical therapy or exercise regimes can then be modified to provide optimal, patient-specific MSK loading to deliver the optimal regenerative response (see Section 4). In addition to the investigation and optimisation of MSK loading, MSK modelling and simulations can be employed in the design and optimisation of active prosthetics to improve motor function. Likewise, critical parameters for pre-surgical planning procedures, implant and assistive device design can be evaluated and their impact on post-intervention functionality evaluated in silico (see Section 5). The applications introduced in this review have a strong emphasis on lower-limb joint contact loading due to the high prevalence in literature and its widespread applications to various MSK conditions. The third section of this review presents a discussion on modelling and simulation considerations and a roadmap for the future integration of MSK modelling and simulations in clinical practice. Indeed, despite clear integration pathways and advantages for clinical applications, the use of 
MSK modelling and simulations remains scarce in standard clinical practice. Poor integration is likely multifactorial with barriers, including lack of easy point-of-care integration, specialist knowledge for use and interpretation and, in some cases, lack of knowledge of the added benefits of MSK modelling and simulations (see Section 8). Additionally, technical limitations exist regarding the accuracy of simulation results, simplifications made within MSK models, and the often cost- and time-intensive frameworks (see Section 7).

\section{Model-Based Analysis of MSK Function}

\subsection{Model Structure}

Musculoskeletal models are, at their core, a mathematical representation of the MSK system (Figure 2). Here, we will describe the general structure of commonly used MSK models. On the simplest level, models contain simplified representations of bones, connected by a series of joints which are then actuated by muscle tendon units (MTU) typically represented as line actuators that have force-producing properties.

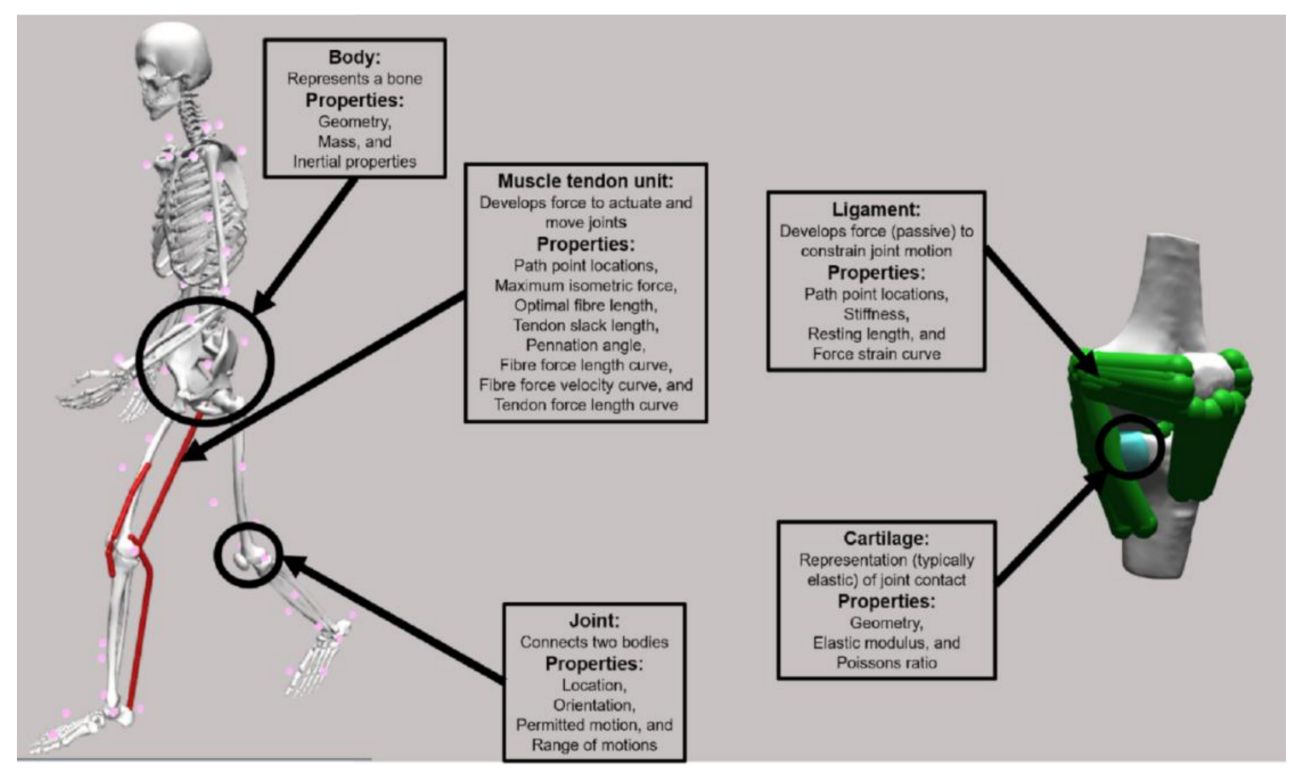

Figure 2. Left: Example of generic full-body MSK model [1] detailing each model component. Displayed are each of the bones, an example of an experimental marker set (pink dots), and the biceps femoris long head, vastus medialis and medial gastrocnemius muscle tendon units. Right: Example of a more complex model $[2,3]$ with representations of ligaments and cartilage surfaces of the tibiofemoral and patellofemoral joint.

Each bone of the skeletal system is represented as a rigid body with a geometry, a mass, and inertial properties.

Joints connect two adjacent bodies and define their articulation (i.e., location and orientation of joint axis around which the body moves) and permitted motions (i.e., degrees of freedom (DOF)). Several different joint definitions are used within MSK models which differ in the number of DOFs (i.e., movement directions). These range in complexity from allowing no movement (weld joint e.g., fibrous joint between the tibia and fibula), permitting a single rotation (hinge joint, e.g., dorsi-/plantar-flexion of the ankle), allowing three rotations (complex ball and socket joint, e.g., hip), all the way up to joints permitting three rotations and three translations (6 DOF joint, e.g., tibiofemoral). Joint kinematics describe how bony and soft tissues limit joint movement (e.g., defining hip rotation range of motion due to the hip capsule). As a result, the permitted range of motion of each DOF is defined, representing these bony and soft tissues structure function, without explicitly modelling 
them. Some models introduce more complex joint definitions, (e.g., through kinematic coupling) which relates an undetermined (i.e., difficult or impossible to measure) DOF to a measured DOF. A specific example of this kinematic coupling is the patellofemoral joint [4]. Given the difficulties in reliably tracking its movement with markers, patella movement is defined as a function of the knee angle rather than based on measured marker positions.

Muscle tendon units span joints and actuate them by developing force along their line of action (i.e., path). In MSK models, muscles and tendons are modelled as a combined unit, hence the term muscle tendon unit. The path of each MTU is defined by an origin and insertion point, but also the intermediate pathway can be specified to represent wrapping over soft tissue or bony structures. This intermediate pathway can be defined using a combination of static or moving points, or analytical surfaces [5]. The pathway determines the elongation of the muscle as a function of the joint movement and by extension the moment arm [6]. The force-producing capacity of the MTU is modelled based on a Hill-type model of muscle contraction [7]. This model describes generic curves describing force generation of active and passive MTU components as a function of length and velocity, thereby capturing the effects of length and contraction velocity on force generation. These generic force-generating curves are made actuator specific by assigning MTU-specific parameters (e.g., maximal isometric force, optimal fibre length, tendon slack length, pennation angle and maximal fibre contraction velocity) to appropriately scale and tune the force-generating capacity.

These MSK models can then be used in combination with 3D experimental gait data (i.e., marker positions, and ground reaction forces) to estimate biomechanical parameters during dynamic function-for example, joint angles—but also muscle activations and forces ultimately allowing calculation of joint contact forces. Such a workflow is referred to as an inverse modelling workflow and consists of the following different steps (Figure 3).

\subsection{Model Customisation}

First, a customised MSK model needs to be generated. This is typically done by scaling a generic model to match the subject's gross anthropometry or by utilising subject-specific geometry obtained from medical imaging.

Scaling of a generic model is performed with the aim of matching the gross anthropometry of a subject. This process linearly scales each body (e.g., femur and pelvis) to match measured segment lengths, anthropometric table values, or most commonly, experimentally acquired motion capture marker positions [8-10]. Along with model geometry, other parameters including joint positions, segment mass and inertia, and MTU pathways are also scaled.

Alternatively, personalised models can be used [11-15]. Using medical imaging segmentation, bone and joint (i.e., cartilage and ligament) geometries and positions, and MTU pathways can also be personalised [11,16,17]. Different types of medical imaging allow the inclusion of different personalised parameters, for example, using computer tomography (CT) information regarding bone geometry can be obtained, however for information regarding soft tissues (i.e., muscle, ligaments, and cartilage) magnetic resonance imaging (MRI) is required. In the absence of complete medical imaging segmentations, statistical shape modelling methods can be utilised to reconstruct complete subject-specific geometry from incomplete data [16,18-20]—see Section 9. The use of 2D ultrasound (US) can provide information regarding MTU parameters (e.g., tendon resting length), and combined with motion capture (i.e., 3D US), information regarding MTU and bone geometry can be obtained [21-26]. The collection of muscle strength data, via dynamometry allows for the customisation of the maximal force-generating capacity (i.e., maximal isometric force) of muscle groups. Further, these dynamometry data can be used to further refine parameters within the previously mentioned Hill-type muscle model [26-29]. Despite the vast number of parameters which can be personalised, the inclusion of the above personalised parameters is uncommon and building fully subject-specific MSK models is rare given the complexity of the additional data collection. Typically, a selection of these personalised data is used to customise existing generic models. 


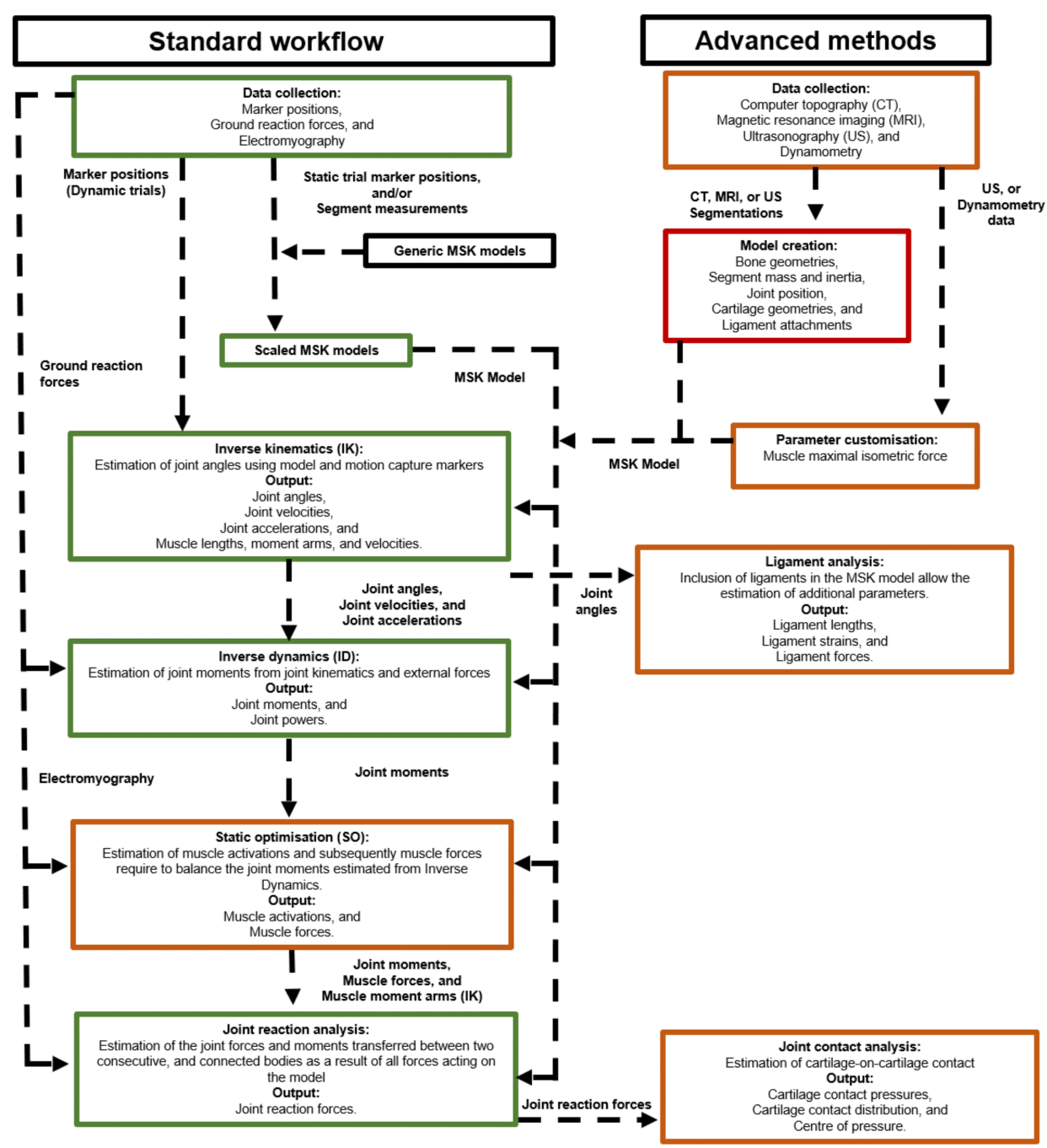

Figure 3. Left: A typical MSK modelling and simulation workflow where data collected in a motion capture laboratory is combined with a MSK model, and modelling and simulation software. Right: Examples of more advanced MSK modelling and simulation methods for creating personalised models and calculation of cartilage on cartilage contact pressure, and ligament forces. Note: colour coding on the boxes indicates the difficulty of performing each task, where green is simple and relatively routine; orange are tasks which are feasible, but can be problematic in specific steps and sensitive to parameters; and red is not impossible, but there are a number of difficulties and a lack of consensus on best practice, making their use uncommon. All coloured boxes represent procedural steps, e.g., data collection and simulation; "free text" represents data passed between procedures, and arrows indicate the flow of data between procedures.

\subsection{Inverse Kinematics}

Once the MSK model has been customised (either through scaling or personalised methods), 3D marker positions acquired within a gait laboratory based on a motion capture system can be used to estimate the joint angles, velocities and accelerations (i.e., joint kinematics) throughout the movement (e.g., walking, running, stair climbing) using an inverse kinematics procedure. In such procedures, the error between recorded marker positions and model marker positions is minimised by varying the segment positions in accordance with the permitted DOFs (i.e., rotations or translations) and imposed constraints [30,31]. The resulting analyses provide an estimated joint angle for each model DOF, at each time point of the specified task. From these kinematic analyses, additional parameters such as MTU length and moment arms can also be estimated. The force-generating 
capacity of the MTU can be calculated, accounting for its length and lengthening velocity, as derived from joint kinematics. Combined with MTU moment arm information, the potential of the MTU to induce segmental acceleration and therefore its contribution to the movement can then be evaluated (i.e., the moment generating capacity of the MTU).

\subsection{Inverse Dynamics}

In a next step, model and estimated kinematics can then be combined with ground reaction forces acquired via force plates to estimate the joint moments during the same movement. To estimate joint moments at each joint, and each DOF, typically an inverse dynamics approach [32] is taken using a classic mechanical formulation. The joint moments represent the resulting action in the joint and are representative of the gross muscle action required during movement.

\subsection{Muscle Activation and Force Estimation}

Following inverse dynamics, individual muscle activations and forces can be estimated which balance the joint moments. Muscle activations are typically estimated using optimisation-based methods that use mathematical criteria to divide the required muscle forces at a joint between all muscles spanning that specific joint. The summed muscle forces must satisfy the constraints of the system (i.e., produce the required muscle moments to balance the joint moments subject to an objective function). Typical objective functions used within the literature are the minimisation of muscle activations to the $n t h$, typically the second, power. Muscle activations and forces can be solved using various optimisation approaches, most commonly static optimization [33-35]. More complex implementations include dynamic optimisation [34,36-38] which can account for more complex muscle tendon dynamics. Another method is computed muscle control $[39,40]$ which couples static optimisation with feedforward and feedback controls to approximate a set of desired kinematics (e.g., from inverse kinematics) and simultaneously estimate both muscle activations and forces. These optimisation methods can be supplemented with experimentally acquired electromyography (EMG) data to constrain estimated muscle activations [41,42]. Calculated muscle activation and force patterns allow researchers and clinicians to imply any changes in muscle function due to different pathologies, or locomotion strategies.

\subsection{Joint Contact Force Estimation}

With knowledge of muscle forces, analyses of joint contact forces can be performed. Typically, MSK models are rigid body models, meaning ligaments and cartilage surfaces are not considered. The output of a typical joint level analysis is therefore an intersegmental contact force [43] considering the joint reaction forces, muscle forces, and body velocities and accelerations. In contrast to finite element analysis (FEA) that provides local tissue loading and deformation, joint contact forces are representative of the overall joint loading given the effect of the forces through foot-ground contact, and the effect of muscle forces. While these approaches give an appreciation for the forces between two bodies, typically these are used as a surrogate for the true variables of interest, cartilage on cartilage contact forces/pressures that can be calculated using more complex models (see below) or different modelling techniques (i.e., FEA).

\subsection{Complex Models and Modelling Approaches}

More advanced models have been developed that include additional components, such as cartilage and ligament surfaces [3,44], allowing the estimation of ligament strains, and forces, along with cartilage on cartilage contact (Figure 3). Estimations of cartilage on cartilage contact has been performed, in MSK models, typically using either an elastic foundation [3] or Hertzian contact model [45], where force is estimated based on overlap or penetration of two surfaces. In addition to cartilage-level analysis, these more complex models allow for ligament level analysis. The inclusion of ligaments in MSK models allows for the estimation of ligament strain and subsequently forces from inverse kinematics 
analysis (i.e., due to changes in joint angle). Furthermore, estimates of ligament forces can be used in the estimations of joint kinematics in complex six DOF joints. Such methods have been applied to the knee joint [3] where estimations of joint kinematics are subject not only to the marker positions, but also cartilage on cartilage contact and ligament forces. These complex MSK models, considering both cartilage and ligaments, provide models and simulation results which can better represent in vivo joint mechanics.

\subsection{Forward Simulations}

An alternate method to the inverse approach detailed above are forward simulation methods which use muscle activations and the resulting muscle force to drive MSK models and subsequently estimate the resulting kinematics and dynamics. As such these models allow users to establish a causal relationship between the forces acting on the human body and the resulting movement, thereby allowing an analysis of 'what if' scenarios. An extension of these forward simulations are predictive simulations, which can be employed to generate novel movements without relying on experimental data. Predictive simulations are typically used to identify muscle excitations and therefore movement patterns that optimise a user-defined cost function (e.g., minimise joint contact forces, muscle fatigue, etc.) subject to constraints describing, among others, the dynamics of the MSK system. These methods exist stand-alone [46] but have also been integrated into existing software packages $[47,48]$.

The following sections will detail specific examples of the use of MSK modelling and simulations and detail pathways for integration into clinical practice. A majority of the detailed applications are focused on lower-limb MSK loading due to the extensive available literature and its relevance to a range of MSK conditions rather than a specific pathology. However, these methods can and have been extending to other segments including the spine [49], upper limbs [50], and head-neck [51].

To conclude, parameters and analyses made available through the use of MSK models and modelling provide valuable information that can be used for not only research studies on clinical populations, but also enhancing clinical treatment pathways, as described below. Indeed, MSK models combined with the tools and methods described above allow detailed analyses of muscle and joint contact forces, in addition to joint angle and moment analysis that most clinical practice software (e.g., Vicon Plug-in-gait (Vicon Motion Systems, Oxford, UK)) provide. Facilitating the adoption of these models are a number of software packages, both commercial (e.g., AnyBody [52]) and open source (e.g., OpenSim $[53,54])$. Both modelling and simulation platforms are typically released with different generic models and are supported by a combination of dedicated developers and their respective research community. The provision of predictive simulation techniques was just recently facilitated through the extension of commonly used software (i.e., OpenSim) to include these predictive simulations as a standard tool $[47,48]$.

\section{Role of Musculoskeletal Models in Disease Prevention and Patient Stratification}

The use of MSK modelling and simulations in cross sectional studies (i.e., single time point) can provide valuable information into disease states and biomarkers (e.g., joint contact forces) that cannot be (easily) measured in vivo. For example, MSK modelling and simulation methods have been applied to patients who have undergone knee ligament reconstructions [55] who are at an elevated risk of osteoarthritis (OA) development. This was previously thought to be driven by higher joint contact forces following reconstructive surgery, it was shown, utilising MSK modelling and simulations, that these patients exhibit lower joint contact forces. This suggests that lower knee joint contact forces, instead of higher, play an important role in OA development. Likewise, others [56] were unable to indicate significant differences in knee joint contact forces in subjects with focal cartilage defects, following traumatic injury. Based on this insight, the magnitude of joint contact forces may be used as a biomarker to monitor disease development in this specific population. These biomarkers can then inform targeted rehabilitation, be used as model-based outcome measures, and as early warning signs or detectors for developing diseases which do not present in typical clinical tests or static medical 
imaging modalities. Likewise, the use of MSK modelling and simulations enables researchers to determine differences in the role of altered mechanical joint environment in OA at different lower-limb joints (i.e., knee vs. hip OA). For example, during gait, joint contact forces in the involved joint is elevated in knee OA [57], whereas elevated joint (i.e., hip) contact forces are not present in hip OA patients $[58,59]$.

Although MSK modelling and simulations are highly valuable in investigating MSK diseases, a potentially more powerful use is in preventing and slowing the progression of different MSK conditions. In this respect, MSK models can be employed within longitudinal trials to study changes in joint contact loading over time [60] (Figure 4). These longitudinal studies allow researchers/clinicians to identify patients who do and do not develop/progress with respect to a specific MSK condition. Examining parameters such as joint moments and in particular joint contact forces would allow researchers/clinicians to identify potentially modifiable parameters to slow disease progression. These biomarkers can then be targeted in rehabilitation such as gait retraining to reduce the likelihood of disease development and limit disease progression. While the above-mentioned longitudinal monitoring has been carried out in typically small cohorts, the type of analysis mentioned above (i.e., biomarker identification) is yet to become mainstream. One of the major limitations is the absence of longitudinal movement analysis data in large longitudinal studies. Including 3D motion capture data in the follow-up of OA patients, together with, medical imaging and various questionnaires which assess subjective disease state, would allow untangling the role of mechanical joint loading in disease progression. With increased computational speed and adequate data collection, these longitudinal studies will become more common in the future as simulation methodologies are more accepted by the medical community.
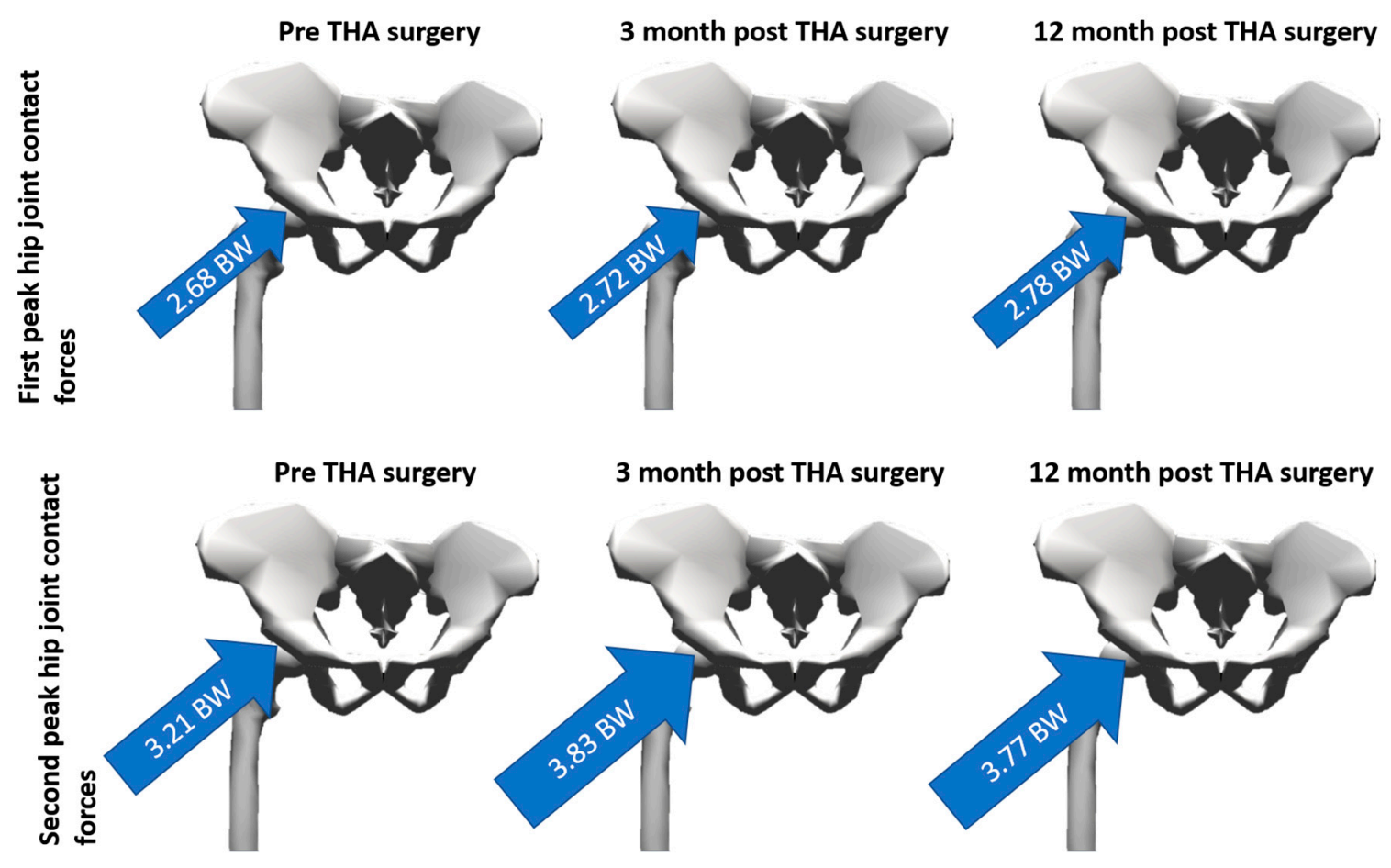

Figure 4. Longitudinal changes in first and second peak hip joint contact forces in patients before, and 3 and 12 months following total hip arthroscopy [60].

\section{Role of Musculoskeletal Models in Rehabilitation}

Along with investigating MSK disease state, and aetiology, MSK modelling and simulations can provide benefits relating to MSK rehabilitation. Rehabilitation is typically aimed at restoring muscle strength, joint stability, or joint loading to a typical or pre-injury state. Prescription of rehabilitation is 
typically based on general guidelines and are not highly tailored to individual patients. It is in this generic prescription where MSK modelling and simulations can enhance the rehabilitation pathway and decision making. By investigating MSK loading during various rehabilitation exercises and determining the load applied to specific tissues, exercise dosage can be tailored to achieve the optimal loading and inform rehabilitation progression [61,62]. Previous research [63] in this area has provided insights into the magnitudes and locations of knee joint loading during different rehabilitation exercises (Figure 5). This information can be particularly useful to personalise the prescribed exercises based on injury location and rehabilitation stage. Utilising the disease biomarkers mentioned previously, the effectiveness of different rehabilitation programs can also be assessed in terms of restoration of typical joint loading or effect on a targeted biomarker. In addition to the investigation and refinement of current clinical guidelines, MSK modelling and simulations can be employed to, for instance, evaluate the effectiveness of new rehabilitation exercises to restore appropriate loading. For example, based on MSK modelling and simulations input, a ranking of exercise regimes was proposed to prevent femoral neck bone loss in females at risk of osteoporosis [64,65]. Using MSK modelling and simulations, compensatory movement strategies to lower knee joint contact forces in patients with knee OA during stair climbing could be identified [57]. These insights may assist clinicians in providing guidelines for rehabilitation of patients to potentially avoid further progression and joint degeneration.

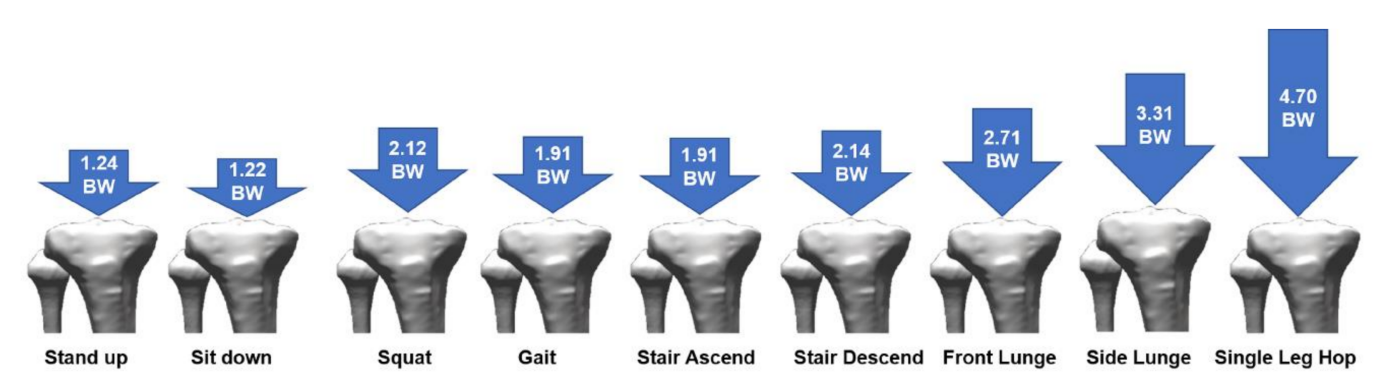

Figure 5. Average tibiofemoral joint contact forces for a range of different functional and rehabilitation tasks [63].

This is even more clear in the field of gait retraining, where the therapist instructs the patient to modify their walking pattern in an attempt to alter the loading on a specific MSK tissue, typically cartilage. These retraining methods have been initially applied to patients with OA whereby specific kinematic gait features (e.g., toe position, trunk lean) are modified to reduce the moments around the knee [66-71] or hip joint [72]. Similar to rehabilitation exercises, these gait retraining goals are based on generic guidelines and the effect on the MSK loading in the individual patient is typically not verified. Over the last decade, the optimisation of MSK modelling and simulation frameworks has driven the development of real-time feedback tools for gait retraining [73-76]. These tools allow clinicians to monitor gait patterns and estimate joint moments in real-time to assess their adherence to the prescribed gait strategy but also to evaluate its effect on MSK loading. Although the testing of different gait strategies can be performed based on experimentally acquired data of the patient's gait, newly developed predictive simulations have been employed to test the effect of an imposed gait strategy on MSK loading without the need for repetitive and time consuming in-person patient assessments. The effect on various MSK tissues can then be investigated to determine if the gait strategy is a viable rehabilitation option. If further developed, this may provide not only optimised treatment planning and likely improved rehabilitation, but also significant time and cost savings for both the patient and clinician. In conclusion, incorporation of MSK modelling and simulations in the evaluation of rehabilitation programs can provide a critical evaluation of the MSK effect of current and proposed rehabilitation strategies and can thus be used to determine if a long term effect of a dedicated program is warranted. Such investigatory studies are currently not standard practice, however the use of MSK modelling approaches to evaluate relevant parameters (i.e., joint contact loading) should be considered for future research. 


\section{Role of Musculoskeletal Models in Pre-Surgical Planning, and Implant and Assistive Device Design}

Previously mentioned clinical treatment applications were primarily focused on physical therapy and rehabilitation, however MSK modelling and simulation applications also extend to orthopaedics. The testing of joint implants has long been performed in the engineering field to improve patient satisfaction, implant lifespan and design, and post-surgical functionality. Implant testing is now often performed using standardised loading procedures, but in the future the use of in silico approaches, performing virtual implant testing will become part of the standard design and testing process enabled and enhanced by MSK modelling and simulations. Using MSK modelling and simulations, population-based or even patient-specific loading parameters (i.e., magnitude and orientation) can be used to perform in silico implant testing, as well as expand on current experimental testing rig protocols. The inclusion of physiological loading data is highly relevant and the logical next step especially in implants which were designed using patient-specific data [77-83]. Another factor also related to the one-size-fits-all design of custom implants, MSK can help in providing guidance to the physical design or alignment of implant components (e.g., femoral head and acetabulum cup positioning-femoral neck off set). Previous studies [84], albeit in native knees, has illustrated the coupling between tibial alignment and knee joint contact force magnitude and location, as well as ligament strains. These insights, in addition to illustrating the importance of tibial component alignment, may serve as guidelines for component alignment during surgery, especially given the importance on soft tissue balancing. Similarly, these assessments have been performed in total knee joint replacements [85-87], investigating the relationship between component alignment and loading parameters (i.e., component stress). Furthermore, using MSK modelling and simulations, identification of gait kinematics which increase the risk of edge loading following total hip replacement could be determined, thereby identifying movement patterns to be corrected during the post-operative phase [72]. Using MSK modelling and simulation workflows, it is already feasible to study the interaction between patient gait characteristics, implant type, and surgical approach, allowing surgeons to optimally tune the surgical intervention based on function rather than patient geometrical features [88]. Ultimately, both design (i.e., sizing, component radius) and alignment (i.e., stem alignment and head angle) parameters can be assessed in silico to design patient-specific implants based on the previously described predictive simulations. This would allow fully optimised post-operative functionality not only at the level of implant loading, but also at the level of gait kinematics and maybe, one day, energy expenditure.

Similar design optimisation (i.e., arch size, location, and manufacturing material) can be applied to shoe insoles to study the effect of variables such as joint contact forces and plantar pressures [89-93] and, more recently, in the optimised design of insoles [94]. This approach is highly relevant in the area of diabetic foot care, where individual insole design is key in preventing foot ulcer formation $[89,95]$. Further, MSK modelling and simulations can be used in the optimisation of assistive devices (Figure 6) and exoskeletons. In addition to the design parameters discussed previously, control of active components (i.e., motor torques) in these devices can be optimised using MSK models and simulations [94,96-99]. With respect to exoskeletons, the use of predictive simulations can be used to optimise control strategy (e.g., for balance control or evaluation of comfort based on contact pressure evaluation $[100,101])$. 


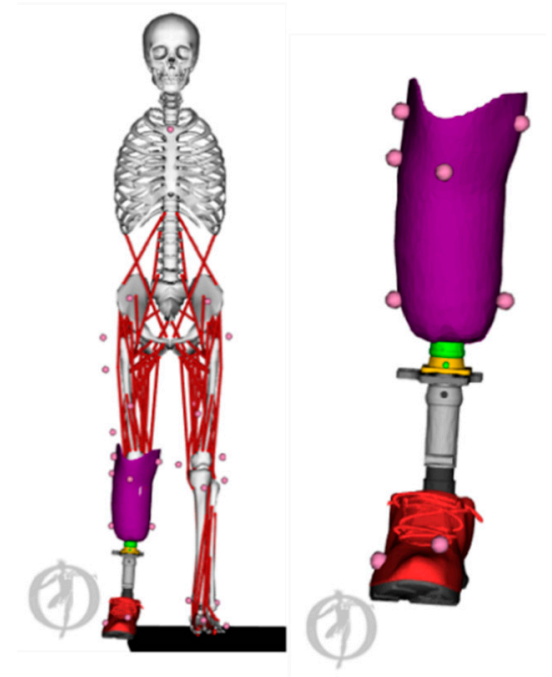

Figure 6. Example of a MSK model implemented in OpenSim which includes a model of a transtibial prosthetic device [102].

\section{Model Validity}

As MSK models and their associated modelling and simulation methods estimate parameters which cannot easily be measured in vivo, direct validation is not always straightforward. As such, various simulation standards are set out within the MSK modelling and simulation community to ensure feasible and valid solutions. These include assessment of errors between acquired and modelled marker trajectories, and assessment of residual forces following inverse dynamics [103]. More advanced validation steps include comparing estimated muscle activations to acquired EMG data to illustrate muscle on-off timings and muscle activation magnitudes. These comparisons are done using correlations where current methods show correlations ranging from 0.46-0.99 [104]. Along with these stand-alone validation steps, some initiatives have provided validation data sets for joint contact forces and joint kinematics derived from instrumented endoprosthesis [105-108]. Using these validation datasets, estimation of joint contact loading magnitude within $0.1-0.5[3,109]$ and $0.5-1.0[110,111]$ body weights for the knee and hip joints, respectively, have been reported. These studies, although showing good agreement with validation data, cannot be carried out for each subject in large cohort studies. A number of studies using these datasets have already provided not only confidence in the modelling and simulation approaches but important methodological advances and consideration [109,112,113]. With such datasets available, and becoming more common, the refinement of methods, and the validity of simulations will continue to improve.

\section{Modelling and Simulation Assumptions}

Although MSK models provide the opportunity to investigate various pathologies and in vivo parameters, just as important as their strengths, limitations are present and must be considered. These limitations relate to both modelling and simulation assumptions and implementations.

A commonly criticised assumption within MSK models is their simplified representation of MTU parameters, and the activation/force estimations. This stems from two origins, first the generic MTU parameters being estimated from cadavers. To partially overcome this, numerous calibration and optimisation techniques have been proposed [41,113-118] and implemented to produce a set of MTU parameters which are likely more accurate than those in generic estimates. Second, the previously mentioned optimisation methods, although providing a set of forces and activations which balance the MSK system, may not accurately represent various features including antagonistic muscle contraction, and muscle spasticity in specific pathologies such as cerebral palsy. With respect to muscle activations, estimates can be improved by using experimentally acquired EMG $[113,119]$. 
Additionally, further processing and pathology-specific procedures have been developed to better represent known differences in muscle function [118]. The sensitivity of simulations to differences in MTU parameters and optimization method have shown variations in estimated hip joint contact force from 2.5 body weights to 5.4 body weights [111].

Along with these MTU related assumptions, simplified representations of anatomy may affect simulation result accuracy. For the lower limbs, the ankle-foot is often represented with a single plantar-/dorsi-flexion DOF despite the numerous joints and DOF present in vivo. This simplification has implications when calculating model parameters [120]. Additionally, the tibiofemoral joint is often represented as a single DOF hinge joint where kinematic constraints are often used for the remaining DOFs. To overcome these joint model simplifications a number of methods have been proposed to more accurately represent in vivo joint motions [121-126]. These simplifications also exist in the upper body where the torso is typically represented as a single unit without muscles and highly simplified articulation not representative for the complexity of spinal movement [49].

\section{Barriers for Clinical Implementation}

The adoption of MSK models, modelling, and simulations into clinical research and practice is hindered by additional barriers, independent of the above modelling and simulation assumptions. The first barrier is knowledge of the benefits of MSK modelling and simulations within clinical practice and the added value and information they can provide. Although within research fields and journals advancements are well documented, transfer of knowledge to relevant clinical partners is often scarce. As such, clinicians may be unaware of cases where MSK models can provide fast and reliable answers to clinically relevant questions. Therefore, there is a clear need for education of the various applications.

Along with education, simple implementation of complicated workflows should be developed and made available to clinicians. These workflows should be able to provide the desired parameters (e.g., joint moments, joint contact forces) without the need to execute complete time-consuming workflows. Such approaches $[127,128]$ have been implemented for simple applications where gastrocnemii and gastrocnemius muscle lengths are estimated using MSK modelling and simulation outputs as reference and clinically feasible measures (i.e., kinematics). Additionally, specific clinically orientated software has been developed for the analysis of gait [129] where simplified approaches have been used, with previous research showing similar accuracy to more complex research driven software [130]. However, the extension of similar interfaces to estimate more complex parameters remain largely unavailable, although some progress is being made in the area of pre-operative planning in cerebral palsy [131]. Along with these easy to use applications, training for both data collection and simulation workflows is imperative for clinical implementation. Additionally, training and simplification of workflow output, will ensure simulation results can be implemented in clinical practice with minimal burden. To ensure MSK simulations are valid and reliable, standardisation of both models and methods is required. A number of different models and frameworks are used throughout research to address different questions; however, to allow comparison of simulation result both between patients and time points, standardisation of modelling frameworks is imperative.

\section{Roadmap for Future Transfer of MSK Modelling and Simulations into Clinics}

The final section of this review provides a roadmap for future applications, developments, and improvements to current MSK modelling and simulation workflows. Several application fields are quickly evolving and will likely provide a next generation of treatment pathways, which build on current applications. Specifically, surgical related applications, both in the design of prosthetics and surgical technique optimisation. Personalised representations of patients, coupled with different implant/prosthetics designs allow for virtual device testing (i.e., loading of the implant/prosthetics). These virtual testing can be performed using a combination of pre-surgical data and predictive simulations. Utilising these predictive simulations further, the effect of different surgical techniques (e.g., femoral de-rotation, tendon transfer) can be refined to achieve the optimal treatment outcomes. 
If these MSK modelling and simulation methods are to be extended to those requiring surgery, accuracy in modelling not only otherwise healthy individuals but those with pathologies is imperative. A specific challenge is appropriately modelling those with motor impairment, and MSK disorders. These may relate to altered muscle activation strategies, bony deformities, or altered MTU characteristics (e.g., muscle weakness). Many of these applications, particularly surgical planning, hinge on highly personalised representation of the MSK system, specifically through subject-specific MSK models.

Despite a number of researchers and groups developing these subject-specific models and modelling platforms, their use especially in clinical research is scarce. This is due to the large amount of data which is required to build these models, along with the cost and time burden to collect this data. Simplification of this personalisation process is required if these models, and applications are to be realised. With respect to anatomical data (i.e., bone segmentations), the use of incomplete or sparse data to synthesize full data is a promising pathway. To this end, the use of statistical shape models (representative of the average shape of a specific population) and associated principal components (describing the shape and size variation) is becoming more common. These methods can use either incomplete segmentations $[18,19,132]$ or a motion capture trial $[18,133,134]$ to reconstruct personalised lower-limb geometries and assemble them into a MSK model. While becoming more common, the application of similar methods to other MSK tissues (muscles, ligaments, and cartilages) would allow for the generation of fully personalised MSK models from low-fidelity clinically feasible data. An alternative approach here is the use of population-based modelling approaches to evaluate model predictions for a range of parameters rather than aiming to accurately represent the individual patient $[135,136]$.

Along with the need to use low-fidelity data to create these models, low-fidelity data for executing these workflows is also required. For example, reducing the need for 3D motion capture, force plate, and EMG data will facilitate the use of MSK models in clinical practice. Using inertia measurement units (IMUs) combined with machine learning and artificial intelligence methods, joint angles, moments, and joint contact forces [137-143] can be estimated in standard clinical practice. These machine learning methods have also been applied to estimate gait speed, cadence, knee flexion angle, and common gait impairment metrics using 2D video [144]. Joint kinematics estimated using such methods could potentially serve as low-fidelity inputs into the previously discussed MSK modelling frameworks. These machine learning methods, combined with low-fidelity data (e.g., IMU, 2D video) will likely provide the most practical clinically feasible assessment of gait. Likewise, collection of a subset of muscle activity may be sufficient to provide an estimated of the muscle coordination strategy without the need of collecting a large number of EMG channel. These data can then be used to improve estimates of muscle forces and activations. Similar to the previously mentioned statistical shape modelling methods, using a subset of collected EMG, muscle activations can be reconstructed through the use of muscle synergy methods [145-149]. However, the use of these low-fidelity data methods, combined with simplified MSK modelling for simulation purposes still needs to be further explored in a research context prior to its adoption in clinics.

In this respect, the adoption of low-fidelity input data for both model creation and execution should however be carefully coupled with both uncertainty and sensitivity analyses to evaluate the set of parameters that have a large effect on simulation results, and as such should be accurately defined. Conversely parameters which have little effect on simulation results can be defined using low-fidelity and less accurate methods, hence reducing the data collection burden. Such analyses have already been performed showing the influence of mass and inertial properties [150]. joint location estimations [123,150], bone-joint geometry and alignment [84,151], muscle parameters [38,152,153], and muscle redundancy formulation [111] on various simulation results including joint moments, muscle force estimates, and joint contact forces. Despite these previous studies, these forms of sensitivity and uncertainty analyses have not been systematically completed on a single dataset, meaning the ranking of these parameters, in terms of simulation sensitivity is difficult to interpret. Additionally, previous research has typically investigated the effect on a single or limited simulation results. As the 
importance of a specific parameter is likely dependent on the output of interest, extensive sensitivity analysis on an output by output basis will provide the ideal balance between data collection burden and simulation validity.

In conclusion, the integration of clinically collected data (i.e., 3D motion capture) with MSK models can provide estimates of numerous clinically relevant parameter related to MSK loading which cannot be estimated using commercially available clinical gait analysis suites. Estimates of these biomarkers can enhance several clinical treatment pathways including rehabilitation, patient stratification, and disease aetiology investigation. Additionally, optimisation of endoprosthesis, prosthetics, assistive devices, and exoskeletons design and controls can be performed using novel predictive simulations. Although numerous clinical applications exist, the adoption of these models and methods are not common, hindered by the specialist knowledge requirements for the execution of workflows and interpretation of results. A specific focus should be increasing the access and useability for non-expert users. This should be accompanied by information regarding appropriate data collection to ensure quality simulation results. Simulation result reports, which give the clinician and patient easy to interpret answers to clinically relevant questions, should be made a priority if these modelling and simulation methods are to be widely adopted. Further integration of MSK modelling and simulations as a clinical tool cannot be achieved by MSK modelling and simulation experts alone, but requires an effort from an interdisciplinary team including modelling and simulation experts and clinicians in order to adequately balance the clinical expectations with the constraints of the modelling and simulation approaches and clinically feasible data.

Author Contributions: All authors (B.A.K., A.F., F.D.G. and I.J.) contributed to the conceptualization and structuring of the work, writing of the original draft, and writing and review of the revised manuscript. All authors have read and agreed to the published version of the manuscript.

Funding: The funders had no role in the design of the study; in the collection, analyses, or interpretation of data; in the writing of the manuscript, or in the decision to publish the results.

Conflicts of Interest: The authors declare no conflict of interest.

\section{References}

1. Rajagopal, A.; Dembia, C.L.; Demers, M.S.; Delp, D.D.; Hicks, J.L.; Delp, S.L. Full-Body Musculoskeletal Model for Muscle-Driven Simulation of Human Gait. IEEE Trans. Biomed. Eng. 2016, 63, 2068-2079. [CrossRef]

2. Lenaerts, G.; De Groote, F.; Demeulenaere, B.; Mulier, M.; Van der Perre, G.; Spaepen, A.; Jonkers, I. Subject-specific hip geometry affects predicted hip joint contact forces during gait. J. Biomech. 2008, 41, 1243-1252. [CrossRef]

3. Smith, C.R.; Vignos, M.F.; Lenhart, R.L.; Kaiser, J.; Thelen, D.G. The Influence of Component Alignment and Ligament Properties on Tibiofemoral Contact Forces in Total Knee Replacement. J. Biomech. Eng. 2016, 138, 21017. [CrossRef]

4. Arnold, E.M.; Ward, S.R.; Lieber, R.L.; Delp, S.L. A Model of the Lower Limb of Analysis of Human Movement. Ann. Biomed. Eng. 2010, 38, 269-279. [CrossRef] [PubMed]

5. Garner, B.A.; Pandy, M.G. The Obstacle Set Method for Representing Muslce Paths in Musculoskeletal Models. Comput. Methods Bioemchan. Biomed. Eng. 2000, 3, 1-30. [CrossRef] [PubMed]

6. Sherman, M.A.; Seth, A.; Delp, S.L. What is a moment arm? Calculating muscle effectiveness in biomechanical models using generalized coordinates. Proc. ASME Des. Eng. Tech. Conf. 2013, 2013, V07BT10A052. [CrossRef]

7. Hill, A. V The Heat of Shortening and the Dynamic Constants of Muscle. Proc. R. Soc. B Biol. Sci. 1938, 126, 136-195.

8. Ziegler, J.; Reiter, A.; Gattringer, H.; Müller, A. Simultaneous identification of human body model parameters and gait trajectory from 3D motion capture data. Med. Eng. Phys. 2020, 84, 193-202. [CrossRef] [PubMed]

9. Lund, M.E.; Andersen, M.S.; de Zee, M.; Rasmussen, J. Scaling of musculoskeletal models from static and dynamic trials. Int. Biomech. 2015, 2, 1-11. [CrossRef] 
10. Ayusawa, K.; Ikegami, Y.; Nakamura, Y. Simultaneous global inverse kinematics and geometric parameter identification of human skeletal model from motion capture data. Mech. Mach. Theory 2014, 74, 274-284. [CrossRef]

11. Scheys, L.; Loeckx, D.; Spaepen, A.; Suetens, P.; Jonkers, I. Atlas-based non-rigid image registration to automatically define line-of-action muscle models: a validation study. J. Biomech. 2009, 42, 565-572. [CrossRef]

12. Modenese, L.; Kohout, J. Automated Generation of Three-Dimensional Complex Muscle Geometries for Use in Personalised Musculoskeletal Models. Ann. Biomed. Eng. 2020, 48, 1793-1804. [CrossRef] [PubMed]

13. Zhang, J.; Sorby, H.; Clement, J.; Thomas, D.L.C.; Hunter, P.; Nielson, P.; Lloyd, D.G.; Taylor, M.; Besier, T.F. The MAP Client: User-Friendly Musculoskeletal Modelling Workflows. In Proceedings of the International Symposium on Biomedical Simulation, Strasbourg, France, 16-17 October 2016; pp. 182-192.

14. Marra, M.A.; Vanheule, V.; Fluit, R.; Koopman, B.H.F.J.M.; Rasmussen, J.; Verdonschot, N.; Andersen, M.S. A subject-specific musculoskeletal modeling framework to predict in vivo mechanics of total knee arthroplasty. J. Biomech. Eng. 2015, 137, 20904. [CrossRef]

15. Valente, G.; Crimi, G.; Vanella, N.; Schileo, E.; Taddei, F. nmsBuilder: Freeware to create subject-specific musculoskeletal models for OpenSim. Comput. Methods Programs Biomed. 2017, 152, 85-92. [CrossRef] [PubMed]

16. Nolte, D.; Tsang, C.K.; Zhang, K.Y.; Ding, Z.; Kedgley, A.E.; Bull, A.M.J. Non-linear scaling of a musculoskeletal model of the lower limb using statistical shape models. J. Biomech. 2016, 49, 3576-3581. [CrossRef]

17. Modenese, L.; Kohout, J. Automated Generation of Three-Dimensional Complex Muscle Geometries for Use in Personalised Musculoskeletal Models. Ann. Biomed. Eng. 2020, 48, 1793-1804. [CrossRef] [PubMed]

18. Davico, G.; Pizzolato, C.; Killen, B.A.; Barzan, M.; Suwarganda, E.; Lloyd, D.G.; Carty, C.P. Reconstruction of paediatric lower limb bones using statistical shape modelling for musculoskeletal modelling. Biomech. Model. Mechanobiol. 2019. [CrossRef]

19. Suwarganda, E.K.; Diamond, L.E.; Lloyd, D.G.; Besier, T.F.; Zhang, J.; Killen, B.A.; Savage, T.N.; Saxby, D.J. Minimal medical imaging can accurately reconstruct geometric bone models for musculoskeletal models. PLoS ONE 2019. [CrossRef]

20. Zhang, J.; Hislop-Jambrish, J.; Besier, T.F. Predictive statistical models of baseline variations in 3-D femoral cortex morphology. Med. Eng. Phys. 2016, 38, 450-457. [CrossRef]

21. Torres, P.M.B.; Sanches, J.M.; Gonçalves, P.J.S.; Martins, J.M.M. 3D femur reconstruction using a robotized ultrasound probe. In Proceedings of the 2012 4th IEEE RAS \& EMBS International Conference on Biomedical Robotics and Biomechatronics (BioRob), Rome, Italy, 24-27 June 2012; pp. 884-888.

22. Barratt, D.C.; Chan, C.S.K.; Edwards, P.J.; Penney, G.P.; Slomczykowski, M.; Carter, T.J.; Hawkes, D.J. Instantiation and registration of statistical shape models of the femur and pelvis using $3 \mathrm{D}$ ultrasound imaging. Med. Image Anal. 2008, 12, 358-374. [CrossRef]

23. Devaprakash, D.; Lloyd, D.G.; Barrett, R.S.; Obst, S.J.; Kennedy, B.; Adams, K.L.; Hunter, A.; Vlahovich, N.; Pease, D.L.; Pizzolato, C. Magnetic Resonance Imaging and Freehand 3-D Ultrasound Provide Similar Estimates of Free Achilles Tendon Shape and 3-D Geometry. Ultrasound Med. Biol. 2019, 45, 2898-2905. [CrossRef] [PubMed]

24. Obst, S.J.; Newsham-West, R.; Barrett, R.S. In vivo measurement of human achilles tendon morphology using freehand 3-D ultrasound. Ultrasound Med. Biol. 2014, 40, 62-70. [CrossRef] [PubMed]

25. Barber, L.; Barrett, R.; Lichtwark, G. Validation of a freehand 3D ultrasound system for morphological measures of the medial gastrocnemius muscle. J. Biomech. 2009, 42, 1313-1319. [CrossRef]

26. Maganaris, C.N. Force-length characteristics of in vivo human skeletal muscle. Acta Physiol. Scand. 2001, 172, 279-285. [CrossRef] [PubMed]

27. Carbone, V.; Van der Krogt, M.M.; Koopman, B.F.J.M.; Verdonschot, N. Subject-specific musculo-tendon parameters based on MRI and dynamometer tests. Gait Posture 2013, 38, S4. [CrossRef]

28. Van Campen, A.; Pipeleers, G.; De Groote, F.; Jonkers, I.; De Schutter, J. A new method for estimating subject-specific muscle-tendon parameters of the knee joint actuators: a simulation study. Int. J. Numer. Method. Biomed. Eng. 2014, 30, 969-987. [CrossRef] [PubMed]

29. Delabastita, T.; Afschrift, M.; Vanwanseele, B.; De Groote, F. Ultrasound-Based Optimal Parameter Estimation Improves Assessment of Calf Muscle-Tendon Interaction During Walking. Ann. Biomed. Eng. 2020, 48, 722-733. [CrossRef] [PubMed] 
30. Lu, T.W.; O'Connor, J.J. Bone position estimation from skin marker co-ordinates using global optimisation with joint constraints. J. Biomech. 1999, 32, 129-134. [CrossRef]

31. De Groote, F.; De Laet, T.; Jonkers, I.; De Schutter, J. Kalman smoothing improves the estimation of joint kinematics and kinetics in marker-based human gait analysis. J. Biomech. 2008, 41, 3390-3398. [CrossRef]

32. Kuo, A.D. A least-squares estimation approach to improving the precision of inverse dynamics computations. J. Biomech. Eng. 1998, 120, 148-159. [CrossRef]

33. An, K.N.; Kaufman, K.R.; Chao, E.Y. Physiological considerations of muscle force through the elbow joint. J. Biomech. 1989, 22, 1249-1256. [CrossRef]

34. Anderson, F.C.; Pandy, M.G. Static and dynamic optimization solutions for gait are practically equivalent. J. Biomech. 2001, 34, 153-161. [CrossRef]

35. Erdemir, A.; McLean, S.; Herzog, W.; van den Bogert, A.J. Model-based estimation of muscle forces exerted during movements. Clin. Biomech. 2007, 22, 131-154. [CrossRef] [PubMed]

36. Andersen, M.S.; Damsgaard, M.; MacWilliams, B.; Rasmussen, J. A computationally efficient optimisation-based method for parameter identification of kinematically determinate and over-determinate biomechanical systems. Comput. Methods Biomech. Biomed. Eng. 2010, 13, 171-183. [CrossRef] [PubMed]

37. Seth, A.; Pandy, M.G. A neuromusculoskeletal tracking method for estimating individual muscle forces in human movement. J. Biomech. 2007, 40, 356-366. [CrossRef]

38. De Groote, F.; Van Campen, A.; Jonkers, I.; De Schutter, J. Sensitivity of dynamic simulations of gait and dynamometer experiments to hill muscle model parameters of knee flexors and extensors. J. Biomech. 2010, 43, 1876-1883. [CrossRef]

39. Thelen, D.G.; Anderson, F.C. Using computed muscle control to generate forward dynamic simulations of human walking from experimental data. J. Biomech. 2006, 39, 1107-1115. [CrossRef]

40. Thelen, D.G.; Anderson, F.C.; Delp, S.L. Generating dynamic simulations of movement using computed muscle control. J. Biomech. 2003, 36, 321-328. [CrossRef]

41. Pizzolato, C.; Lloyd, D.G.; Sartori, M.; Ceseracciu, E.; Besier, T.F.; Fregly, B.J.; Reggiani, M. CEINMS: A toolbox to investigate the influence of different neural control solutions on the prediction of muscle excitation and joint moments during dynamic motor tasks. J. Biomech. 2015, 48, 3929-3936. [CrossRef]

42. Lloyd, D.G.; Besier, T.F. An EMG-driven musculoskeletal model to estimate muscle forces and knee joint moments in vivo. J. Biomech. 2003, 36, 765-776. [CrossRef]

43. Steele, K.M.; Demers, M.S.; Schwartz, M.H.; Delp, S.L. Compressive tibiofemoral force during crouch gait. Gait Posture 2012, 35, 556-560. [CrossRef] [PubMed]

44. Xu, H.; Bloswick, D.; Merryweather, A. An improved OpenSim gait model with multiple degrees of freedom knee joint and knee ligaments. Comput. Methods Biomech. Biomed. Eng. 2015, 18, 1217-1224. [CrossRef] [PubMed]

45. Eskinazi, I.; Fregly, B.J. An Open-Source Toolbox for Surrogate Modeling of Joint Contact Mechanics. IEEE Trans. Biomed. Eng. 2016, 63, 269-277. [CrossRef]

46. Falisse, A.; Serrancoli, G.; Dembia, C.L.; Gillis, J.; Jonkers, I.; De Groote, F. Rapid predictive simulations with complex musculoskeletal models suggest that diverse healthy and pathological human gaits can emerge from similar control strategies. J. R. Soc. Interface 2019, 16, 20190402. [CrossRef]

47. Dembia, C.; Bianco, N.; Falisse, A.; Hicks, J.; Delp, S. OpenSim Moco: Musculoskeletal optimal control. bioRxiv 2019. [CrossRef]

48. Geijtenbeek, T. SCONE: Open Source Software for Predictive Simulation of Biological Motion'. J. Open Source Softw. 2019, 4. [CrossRef]

49. Wang, W.; Wang, D.; De Groote, F.; Scheys, L.; Jonkers, I. Implementation of physiological functional spinal units in a rigid-body model of the thoracolumbar spine. J. Biomech. 2020, 98, 109437. [CrossRef]

50. Ackland, D.C.; Roshan-Zamir, S.; Richardson, M.; Pandy, M.G. Muscle and joint-contact loading at the glenohumeral joint after reverse total shoulder arthroplasty. J. Orthop. Res. 2011, 29, 1850-1858. [CrossRef] [PubMed]

51. Vasavada, A.N.; Li, S.; Delp, S.L. Influence of muscle morphometry and moment arms on the moment-generating capacity of human neck muscles. Spine 1998, 23, 412-422. [CrossRef]

52. Damsgaard, M.; Rasmussen, J.; Christensen, S.T.; Surma, E.; de Zee, M. Analysis of musculoskeletal systems in the AnyBody Modeling System. Simul. Model. Pr. Theory 2006, 14, 1100-1111. [CrossRef] 
53. Delp, S.L.; Loan, J.P.; Hoy, M.G.; Zajac, F.E.; Topp, E.L.; Rosen, J.M. An interactive graphics-based model of the lower extremity to study orthopaedic surgical procedures. IEEE Trans. Biomed. Eng. 1990, 37, 757-767. [CrossRef]

54. Seth, A.; Hicks, J.L.; Uchida, T.K.; Habib, A.; Dembia, C.L.; Dunne, J.J.; Ong, C.F.; DeMers, M.S.; Rajagopal, A.; Millard, M.; et al. OpenSim: Simulating musculoskeletal dynamics and neuromuscular control to study human and animal movement. PLoS Comput. Biol. 2018, 14, e1006223. [CrossRef] [PubMed]

55. Saxby, D.J.; Bryant, A.L.; Modenese, L.; Gerus, P.; Killen, B.A.; Konrath, J.; Fortin, K.; Wrigley, T.V.; Bennell, K.L.; Cicuttini, F.M.; et al. Tibiofemoral Contact Forces in the Anterior Cruciate Ligament-Reconstructed Knee. Med. Sci. Sports Exerc. 2016, 48, 2195-2206. [CrossRef]

56. Van Rossom, S.; Khatib, N.; Holt, C.; Van Assche, D.; Jonkers, I. Subjects with medial and lateral tibiofemoral articular cartilage defects do not alter compartmental loading during walking. Clin. Biomech. (BristolAvon) 2018, 60, 149-156. [CrossRef]

57. Meireles, S.; Wesseling, M.; Smith, C.R.; Thelen, D.G.; Verschueren, S.; Jonkers, I. Medial knee loading is altered in subjects with early osteoarthritis during gait but not during step-up-and-over task. PLoS ONE 2017, 12, e0187583. [CrossRef]

58. Meyer, C.A.G.; Wesseling, M.; Corten, K.; Nieuwenhuys, A.; Monari, D.; Simon, J.-P.; Jonkers, I.; Desloovere, K. Hip movement pathomechanics of patients with hip osteoarthritis aim at reducing hip joint loading on the osteoarthritic side. Gait Posture 2018, 59, 11-17. [CrossRef] [PubMed]

59. Wesseling, M.; de Groote, F.; Meyer, C.; Corten, K.; Simon, J.-P.; Desloovere, K.; Jonkers, I. Gait alterations to effectively reduce hip contact forces. J. Orthop. Res. Off. Publ. Orthop. Res. Soc. 2015, 33, 1094-1102. [CrossRef]

60. Wesseling, M.; Meyer, C.; Corten, K.; Desloovere, K.; Jonkers, I. Longitudinal joint loading in patients before and up to one year after unilateral total hip arthroplasty. Gait Posture 2018, 61, 117-124. [CrossRef]

61. Mobasheri, A.; Batt, M. An update on the pathophysiology of osteoarthritis. Ann. Phys. Rehabil. Med. 2016, 59, 333-339. [CrossRef]

62. Karsdal, M.A.; Christiansen, C.; Ladel, C.; Henriksen, K.; Kraus, V.B.; Bay-Jensen, A.C. Osteoarthritis-A case for personalized health care? Osteoarthr. Cart. 2014, 22, 7-16. [CrossRef] [PubMed]

63. Van Rossom, S.; Smith, C.R.; Thelen, D.G.; Vanwanseele, B.; Van Assche, D.; Jonkers, I. Knee Joint Loading in Healthy Adults During Functional Exercises: Implications for Rehabilitation Guidelines. J. Orthop. Sports Phys. 2018, 48, 162-173. [CrossRef]

64. Pellikaan, P.; Giarmatzis, G.; Vander Sloten, J.; Verschueren, S.; Jonkers, I. Ranking of osteogenic potential of physical exercises in postmenopausal women based on femoral neck strains. PLOS ONE 2018, 13, e0195463. [CrossRef]

65. Giarmatzis, G.; Jonkers, I.; Baggen, R.; Verschueren, S. Less hip joint loading only during running rather than walking in elderly compared to young adults. Gait Posture 2017, 53, 155-161. [CrossRef] [PubMed]

66. Favre, J.; Erhart-Hledik, J.C.; Chehab, E.F.; Andriacchi, T.P. General scheme to reduce the knee adduction moment by modifying a combination of gait variables. J. Orthop. Res. 2016, 34, 1547-1556. [CrossRef]

67. Gerbrands, T.A.; Pisters, M.F.; Vanwanseele, B. Individual selection of gait retraining strategies is essential to optimally reduce medial knee load during gait. Clin. Biomech. 2014, 29, 828-834. [CrossRef] [PubMed]

68. Gerbrands, T.A.; Pisters, M.F.; Theeven, P.J.R.; Verschueren, S.; Vanwanseele, B. Lateral trunk lean and medializing the knee as gait strategies for knee osteoarthritis. Gait Posture 2017, 51, 247-253. [CrossRef]

69. Shull, P.B.; Silder, A.; Shultz, R.; Dragoo, J.L.; Besier, T.F.; Delp, S.L.; Cutkosky, M.R. Six-week gait retraining program reduces knee adduction moment, reduces pain, and improves function for individuals with medial compartment knee osteoarthritis. J. Orthop. Res. 2013, 31, 1020-1025. [CrossRef]

70. Shull, P.B.; Lurie, K.L.; Cutkosky, M.R.; Besier, T.F. Training multi-parameter gaits to reduce the knee adduction moment with data-driven models and haptic feedback. J. Biomech. 2011, 44, 1605-1609. [CrossRef] [PubMed]

71. Uhlrich, S.D.; Silder, A.; Beaupre, G.S.; Shull, P.B.; Delp, S.L. Subject-specific toe-in or toe-out gait modifications reduce the larger knee adduction moment peak more than a non-personalized approach. J. Biomech. 2018, 66, 103-110. [CrossRef]

72. Wesseling, M.; Meyer, C.; De Groote, F.; Corten, K.; Simon, J.-P.; Desloovere, K.; Jonkers, I. Gait alterations can reduce the risk of edge loading. J. Orthop. Res. Off. Publ. Orthop. Res. Soc. 2016, 34, 1069-1076. [CrossRef] 
73. Van Den Noort, J.C.; Steenbrink, F.; Roeles, S.; Harlaar, J. Real-time visual feedback for gait retraining: toward application in knee osteoarthritis. Med. Biol. Eng. Comput. 2015, 53, 275-286. [CrossRef]

74. Pizzolato, C.; Reggiani, M.; Saxby, D.J.; Ceseracciu, E.; Modenese, L.; Lloyd, D.G. Biofeedback for Gait Retraining Based on Real-Time Estimation of Tibiofemoral Joint Contact Forces. IEEE Trans. Neural Syst. Rehabil. Eng. 2017, 25, 1612-1621. [CrossRef] [PubMed]

75. Pizzolato, C.; Reggiani, M.; Modenese, L.; Lloyd, D.G. Real-time inverse kinematics and inverse dynamics for lower limb applications using OpenSim. Comput. Methods Biomech. Biomed. Eng. 2017, 20, 436-445. [CrossRef]

76. Fregly, B.J.; Reinbolt, J.A.; Rooney, K.L.; Mitchell, K.H.; Chmielewski, T.L. Design of patient-specific gait modifications for knee osteoarthritis rehabilitation. IEEE Trans. Biomed. Eng. 2007, 54, 1687-1695. [CrossRef] [PubMed]

77. Lombardi, A.V.J.; Berend, K.R.; Adams, J.B. Patient-specific approach in total knee arthroplasty. Orthopedics 2008, 31, 927-930. [CrossRef] [PubMed]

78. Fitz, W. Unicompartmental Knee Arthroplasty with Use of Novel Patient-Specific Resurfacing Implants and Personalized Jigs. JBJS 2009, 91, 69-76. [CrossRef]

79. Jun, Y.; Choi, K. Design of patient-specific hip implants based on the 3D geometry of the human femur. Adv. Eng. Softw. 2010, 41, 537-547. [CrossRef]

80. Dérand, P.; Rännar, L.-E.; Hirsch, J.-M. Imaging, Virtual Planning, Design, and Production of Patient-Specific Implants and Clinical Validation in Craniomaxillofacial Surgery. Craniomaxillofac. Trauma Reconstr. 2012, 5, 137-143. [CrossRef]

81. Demange, M.K.; Von Keudell, A.; Probst, C.; Yoshioka, H.; Gomoll, A.H. Patient-specific implants for lateral unicompartmental knee arthroplasty. Int. Orthop. 2015, 39, 1519-1526. [CrossRef]

82. Ackland, D.C.; Robinson, D.; Redhead, M.; Lee, P.V.S.; Moskaljuk, A.; Dimitroulis, G. A personalized 3D-printed prosthetic joint replacement for the human temporomandibular joint: From implant design to implantation. J. Mech. Behav. Biomed. Mater. 2017, 69, 404-411. [CrossRef]

83. Jonkers, I.; Sauwen, N.; Lenaerts, G.; Mulier, M.; Van der Perre, G.; Jaecques, S. Relation between subject-specific hip joint loading, stress distribution in the proximal femur and bone mineral density changes after total hip replacement. J. Biomech. 2008, 41, 3405-3413. [CrossRef]

84. Van Rossom, S.; Wesseling, M.; Smith, C.R.; Thelen, D.G.; Vanwanseele, B.; Dieter, V.A.; Jonkers, I. The influence of knee joint geometry and alignment on the tibiofemoral load distribution: A computational study. Knee 2019, 26, 813-823. [CrossRef] [PubMed]

85. Gromov, K.; Korchi, M.; Thomsen, M.G.; Husted, H.; Troelsen, A. What is the optimal alignment of the tibial and femoral components in knee arthroplasty? Acta Orthop. 2014, 85, 480-487. [CrossRef] [PubMed]

86. Innocenti, B.; Bellemans, J.; Catani, F. Deviations From Optimal Alignment in TKA: Is There a Biomechanical Difference Between Femoral or Tibial Component Alignment? J. Arthroplast. 2016, 31, 295-301. [CrossRef] [PubMed]

87. Vanheule, V.; Delport, H.P.; Andersen, M.S.; Scheys, L.; Wirix-Speetjens, R.; Jonkers, I.; Victor, J.; Vander Sloten, J. Evaluation of predicted knee function for component malrotation in total knee arthroplasty. Med. Eng. Phys. 2017, 40, 56-64. [CrossRef]

88. Wesseling, M.; Meyer, C.; Corten, K.; Simon, J.-P.; Desloovere, K.; Jonkers, I. Does surgical approach or prosthesis type affect hip joint loading one year after surgery? Gait Posture 2016, 44, 74-82. [CrossRef] [PubMed]

89. Aerts, W.; Scarton, A.; De Groote, F.; Guiotto, A.; Sawacha, Z.; Cobelli, C.; Vander Sloten, J.; Jonkers, I. Validation of plantar pressure simulations using finite and discrete element modelling in healthy and diabetic subjects. Comput. Methods Biomech. Biomed. Eng. 2017, 20, 1442-1452. [CrossRef] [PubMed]

90. Guldemond, N.A.; Leffers, P.; Schaper, N.C.; Sanders, A.P.; Nieman, F.; Willems, P.; Walenkamp, G.H.I.M. The effects of insole configurations on forefoot plantar pressure and walking convenience in diabetic patients with neuropathic feet. Clin. Biomech. 2007, 22, 81-87. [CrossRef]

91. Lemmon, D.; Shiang, T.Y.; Hashmi, A.; Ulbrecht, J.S.; Cavanagh, P.R. The effect of insoles in therapeutic footwear-A finite element approach. J. Diabetes Complicat. 1997, 30, 615-620. [CrossRef]

92. Nigg, B.M.; Stergiou, P.; Cole, G.; Stefanyshyn, D.; Mündermann, A.; Humble, N. Effect of shoe inserts on kinematics, center of pressure, and leg joint moments during running. Med. Sci. Sports Exerc. 2003, 35, 314-319. [CrossRef] 
93. Uccioli, L.; Faglia, E.; Monticone, G.; Favales, F.; Durola, L.; Aldeghi, A.; Quarantiello, A.; Calia, P.; Menzinger, G. Manufactured Shoes in the Prevention of Diabetic Foot Ulcers. Diabetes Care 1995, 18, 1376LP-1378LP. [CrossRef]

94. Rohani, F.; Richter, H.; van den Bogert, A.J. Optimal design and control of an electromechanical transfemoral prosthesis with energy regeneration. PLOS ONE 2017, 12, e0188266. [CrossRef] [PubMed]

95. Scarton, A.; Guiotto, A.; Malaquias, T.; Spolaor, F.; Sinigaglia, G.; Cobelli, C.; Jonkers, I.; Sawacha, Z. A methodological framework for detecting ulcers' risk in diabetic foot subjects by combining gait analysis, a new musculoskeletal foot model and a foot finite element model. Gait Posture 2018, 60, 279-285. [CrossRef]

96. Eilenberg, M.F.; Geyer, H.; Herr, H. Control of a powered ankle-foot prosthesis based on a neuromuscular model. IEEE Trans. Neural Syst. Rehabil. Eng. 2010, 18, 164-173. [CrossRef] [PubMed]

97. Handford, M.L.; Srinivasan, M. Robotic lower limb prosthesis design through simultaneous computer optimizations of human and prosthesis costs. Sci. Rep. 2016, 6, 19983. [CrossRef] [PubMed]

98. Thatte, N.; Geyer, H. Toward Balance Recovery With Leg Prostheses Using Neuromuscular Model Control. IEEE Trans. Biomed. Eng. 2016, 63, 904-913. [CrossRef]

99. Wu, A.R.; Dzeladini, F.; Brug, T.J.H.; Tamburella, F.; Tagliamonte, N.L.; van Asseldonk, E.H.F.; van der Kooij, H.; Ijspeert, A.J. An Adaptive Neuromuscular Controller for Assistive Lower-Limb Exoskeletons: A Preliminary Study on Subjects with Spinal Cord Injury. Front. Neurorobot. 2017, 11, 30. [CrossRef]

100. Vantilt, J.; Tanghe, K.; Afschrift, M.; Bruijnes, A.K.B.D.; Junius, K.; Geeroms, J.; Aertbeliën, E.; De Groote, F.; Lefeber, D.; Jonkers, I.; et al. Model-based control for exoskeletons with series elastic actuators evaluated on sit-to-stand movements. J. Neuroeng. Rehabil. 2019, 16, 65. [CrossRef]

101. Serrancoli, G.; Falisse, A.; Dembia, C.; Vantilt, J.; Tanghe, K.; Lefeber, D.; Jonkers, I.; De Schutter, J.; De Groote, F. Subject-Exoskeleton Contact Model Calibration Leads to Accurate Interaction Force Predictions. IEEE Trans. Neural Syst. Rehabil. Eng. Publ. IEEE Eng. Med. Biol. Soc. 2019, 27, 1597-1605. [CrossRef]

102. Aerts, W.; Creylman, V.; Vander Sloten, J.; Jonkers, I. Extension and anterior alignment of the prosthetic foot normalizes hip and knee loading symmetry in unilateral trans-tibial amputees. GaitPosture 2016, 49, 127.

103. Hicks, J.L.; Uchida, T.K.; Seth, A.; Rajagopal, A.; Delp, S.L. Is my model good enough? Best practices for verification and validation of musculoskeletal models and simulations of movement. J. Biomech. Eng. 2015, 137, 20905. [CrossRef]

104. Lin, Y.-C.; Dorn, T.W.; Schache, A.G.; Pandy, M.G. Comparison of different methods for estimating muscle forces in human movement. Proc. Inst. Mech. Eng. Part. H J. Eng. Med. 2011, 226, 103-112. [CrossRef]

105. Bergmann, G.; Graichen, F.; Rohlmann, A. Hip joint contact forces during stumbling. Langenbeck's Arch. Surg. 2004, 389, 53-59. [CrossRef] [PubMed]

106. Bergmann, G.; Graichen, F.; Rohlmann, A.; Bender, A.; Heinlein, B.; Duda, G.N.; Heller, M.O.; Morlock, M.M. Realistic loads for testing hip implants. Biomed. Mater. Eng. 2010, 20, 65-75. [CrossRef] [PubMed]

107. Fregly, B.J.; Besier, T.F.; Lloyd, D.G.; Delp, S.L.; Banks, S.A.; Pandy, M.G.; D’Lima, D.D. Grand challenge competition to predict in vivo knee loads. J. Orthop. Res. 2012, 30,503-513. [CrossRef]

108. Taylor, W.R.; Schütz, P.; Bergmann, G.; List, R.; Postolka, B.; Hitz, M.; Dymke, J.; Damm, P.; Duda, G.; Gerber, H.; et al. A comprehensive assessment of the musculoskeletal system: The CAMS-Knee data set. J. Biomech. 2017, 65, 32-39. [CrossRef]

109. Gerus, P.; Sartori, M.; Besier, T.F.; Fregly, B.J.; Delp, S.L.; Banks, S.A.; Pandy, M.G.; D’Lima, D.D.; Lloyd, D.G. Subject-specific knee joint geometry improves predictions of medial tibiofemoral contact forces. J. Biomech. 2013, 9, 2-9. [CrossRef]

110. Weinhandl, J.T.; Bennett, H.J. Musculoskeletal model choice influences hip joint load estimations during gait. J. Biomech. 2019, 91, 124-132. [CrossRef]

111. Hoang, H.X.; Pizzolato, C.; Diamond, L.E.; Lloyd, D.G. Subject-specific calibration of neuromuscular parameters enables neuromusculoskeletal models to estimate physiologically plausible hip joint contact forces in healthy adults. J. Biomech. 2018, 80, 111-120. [CrossRef]

112. Zargham, A.; Afschrift, M.; De Schutter, J.; Jonkers, I.; De Groote, F. Inverse dynamic estimates of muscle recruitment and joint contact forces are more realistic when minimizing muscle activity rather than metabolic energy or contact forces. Gait Posture 2019, 74, 223-230. [CrossRef] [PubMed]

113. Hoang, H.X.; Diamond, L.E.; Lloyd, D.G.; Pizzolato, C. A calibrated EMG-informed neuromusculoskeletal model can appropriately account for muscle co-contraction in the estimation of hip joint contact forces in people with hip osteoarthritis. J. Biomech. 2019, 83, 134-142. [CrossRef] 
114. Hainisch, R.; Gfoehler, M.; Zubayer-Ul-Karim, M.; Pandy, M.G. Method for determining musculotendon parameters in subject-specific musculoskeletal models of children developed from MRI data. Multibody Syst. Dyn. 2012, 28, 143-156. [CrossRef]

115. Modenese, L.; Ceseracciu, E.; Reggiani, M.; Lloyd, D.G. Estimation of musculotendon parameters for scaled and subject specific musculoskeletal models using an optimization technique. J. Biomech. 2016, 49, 141-148. [CrossRef] [PubMed]

116. Serrancolí, G.; Kinney, A.L.; Fregly, B.J.; Font-Llagunes, J.M. Neuromusculoskeletal Model Calibration Significantly Affects Predicted Knee Contact Forces for Walking. J. Biomech. Eng. 2016, 138, 810011-8100111. [CrossRef]

117. Winby, C.R.; Lloyd, D.G.; Kirk, T.B. Evaluation of different analytical methods for subject-specific scaling of musculotendon parameters. J. Biomech. 2008, 41, 1682-1688. [CrossRef] [PubMed]

118. Falisse, A.; Bar-On, L.; Desloovere, K.; Jonkers, I.; De Groote, F. A spasticity model based on feedback from muscle force explains muscle activity during passive stretches and gait in children with cerebral palsy. PLoS ONE 2018, 13, e0208811. [CrossRef]

119. Falisse, A.; Van Rossom, S.; Jonkers, I.; De Groote, F. EMG-Driven Optimal Estimation of Subject-SPECIFIC Hill Model Muscle-Tendon Parameters of the Knee Joint Actuators. IEEE Trans. Biomed. Eng. 2017, 64, 2253-2262. [CrossRef]

120. Zelik, K.E.; Honert, E.C. Ankle and foot power in gait analysis: Implications for science, technology and clinical assessment. J. Biomech. 2018, 75, 1-12. [CrossRef]

121. Malaguias, T.M.; Silveira, C.; Aerts, W.; De Groote, F.; Dereymaeker, G.; Vander Sloten, J.; Jonkers, J. Extended foot-ankle musculoskeletal models for application in movement analysis. Comput. Methods Biomech. Biomed. Eng. 2017, 20, 153-159. [CrossRef]

122. Montefiori, E.; Modenese, L.; Di Marco, R.; Magni-Manzoni, S.; Malattia, C.; Petrarca, M.; Ronchetti, A.; de Horatio, L.T.; van Dijkhuizen, P.; Wang, A.; et al. An image-based kinematic model of the tibiotalar and subtalar joints and its application to gait analysis in children with Juvenile Idiopathic Arthritis. J. Biomech. 2019, 85, 27-36. [CrossRef]

123. Kainz, H.; Carty, C.P.; Maine, S.; Walsh, H.P.J.; Lloyd, D.G.; Modenese, L. Effects of hip joint centre mislocation on gait kinematics of children with cerebral palsy calculated using patient-specific direct and inverse kinematic models. Gait Posture 2017, 57, 154-160. [CrossRef]

124. Dzialo, C.M.; Pedersen, P.H.; Simonsen, C.W.; Jensen, K.K.; de Zee, M.; Andersen, M.S. Development and validation of a subject-specific moving-axis tibiofemoral joint model using MRI and EOS imaging during a quasi-static lunge. J. Biomech. 2018, 72, 71-80. [CrossRef]

125. Modenese, L.; Montefiori, E.; Wang, A.; Wesarg, S.; Viceconti, M.; Mazzà, C. Investigation of the dependence of joint contact forces on musculotendon parameters using a codified workflow for image-based modelling. J. Biomech. 2018, 73, 108-118. [CrossRef] [PubMed]

126. Barzan, M.; Modenese, L.; Carty, C.P.; Maine, S.; Stockton, C.A.; Sancisi, N.; Lewis, A.; Grant, J.; Lloyd, D.G.; Brito da Luz, S. Development and validation of subject-specific pediatric multibody knee kinematic models with ligamentous constraints. J. Biomech. 2019, 93, 194-203. [CrossRef] [PubMed]

127. Stewart, C.; Jonkers, I.; Roberts, A. Estimation of hamstring length at initial contact based on kinematic gait data. Gait Posture 2004, 20, 61-66. [CrossRef]

128. Rajagopal, A.; Kidziński, Ł.; McGlaughlin, A.S.; Hicks, J.L.; Delp, S.L.; Schwartz, M.H. Pre-operative gastrocnemius lengths in gait predict outcomes following gastrocnemius lengthening surgery in children with cerebral palsy. PLoS ONE 2020, 15, e0233706. [CrossRef]

129. van den Bogert, A.J.; Geijtenbeek, T.; Even-Zohar, O.; Steenbrink, F.; Hardin, E.C. A real-time system for biomechanical analysis of human movement and muscle function. Med. Biol. Eng. Comput. 2013, 51, 1069-1077. [CrossRef]

130. Falisse, A.; Van Rossom, S.; Gijsbers, J.; Steenbrink, F.; van Basten, B.J.H.; Jonkers, I.; van den Bogert, A.J.; De Groote, F. OpenSim Versus Human Body Model: A Comparison Study for the Lower Limbs During Gait. J. Appl. Biomech. 2018, 1-7. [CrossRef]

131. Pitto, L.; Kainz, H.; Falisse, A.; Wesseling, M.; Van Rossom, S.; Hoang, H.; Papageorgiou, E.; Hallemans, A.; Desloovere, K.; Molenaers, G.; et al. SimCP: A Simulation Platform to Predict Gait Performance Following Orthopedic Intervention in Children With Cerebral Palsy. Front. Neurorobot. 2019, 13, 54. [CrossRef] 
132. Bahl, J.S.; Zhang, J.; Killen, B.A.; Taylor, M.; Soloman, L.B.; Arnold, J.B.; Lloyd, D.G.; Besier, T.F.; Thewlis, D. Statistical shape modelling versus linear scaling: effects on predictions of hip joint centre location and muscle moment arms in people with hip osteoarthritis. J. Biomech. 2019, 85, 164-172. [CrossRef]

133. Bakke, D.; Besier, T. Shape model constrained scaling improves repeatability of gait data. J. Biomech. 2020, 107, 109838. [CrossRef]

134. Zhang, J.; Fernandez, J.; Hislop-Jambrish, J.; Besier, T.F. Lower limb estimation from sparse landmarks using an articulated shape model. J. Biomech. 2016, 49, 3875-3881. [CrossRef]

135. Valente, G.; Taddei, F.; Jonkers, I. Influence of weak hip abductor muscles on joint contact forces during normal walking: probabilistic modeling analysis. J. Biomech. 2013, 46, 2186-2193. [CrossRef]

136. Bosmans, L.; Valente, G.; Wesseling, M.; Van Campen, A.; De Groote, F.; De Schutter, J.; Jonkers, I. Sensitivity of predicted muscle forces during gait to anatomical variability in musculotendon geometry. J. Biomech. 2015, 48, 2116-2123. [CrossRef] [PubMed]

137. Karatsidis, A.; Bellusci, G.; Schepers, H.M.; de Zee, M.; Andersen, M.S.; Veltink, P.H. Estimation of Ground Reaction Forces and Moments During Gait Using Only Inertial Motion Capture. Sensors 2016, 17, 75. [CrossRef] [PubMed]

138. Johnson, W.R.; Mian, A.; Donnelly, C.J.; Lloyd, D.; Alderson, J. Predicting athlete ground reaction forces and moments from motion capture. Med. Biol. Eng. Comput. 2018, 56, 1781-1792. [CrossRef] [PubMed]

139. Johnson, W.R.; Alderson, J.; Lloyd, D.; Mian, A. Predicting Athlete Ground Reaction Forces and Moments From Spatio-Temporal Driven CNN Models. IEEE Trans. Biomed. Eng. 2019, 66, 689-694. [CrossRef]

140. Tagliapietra, L.; Modenese, L.; Ceseracciu, E.; Mazzà, C.; Reggiani, M. Validation of a model-based inverse kinematics approach based on wearable inertial sensors. Comput. Methods Biomech. Biomed. Eng. 2018, 21, 834-844. [CrossRef] [PubMed]

141. Konrath, J.; Karatsidis, A.; Schepers, H.; Bellusci, G.; de Zee, M.; Andersen, M. Estimation of the Knee Adduction Moment and Joint Contact Force during Daily Living Activities Using Inertial Motion Capture. Sensors 2019, 19, 1681. [CrossRef]

142. De Brabandere, A.; Emmerzaal, J.; Timmermans, A.; Jonkers, I.; Vanwanseele, B.; Davis, J. A Machine Learning Approach to Estimate Hip and Knee Joint Loading Using a Mobile Phone-Embedded IMU. Front. Bioeng. Biotechnol. 2020, 8, 320. [CrossRef]

143. Stetter, B.J.; Krafft, F.C.; Ringhof, S.; Stein, T.; Sell, S. A Machine Learning and Wearable Sensor Based Approach to Estimate External Knee Flexion and Adduction Moments During Various Locomotion Tasks. Front. Bioeng. Biotechnol. 2020, 8, 9. [CrossRef]

144. Kidziński, Ł.; Yang, B.; Hicks, J.L.; Rajagopal, A.; Delp, S.L.; Schwartz, M.H. Deep neural networks enable quantitative movement analysis using single-camera videos. Nat. Commun. 2020, 11, 4054. [CrossRef] [PubMed]

145. Pitto, L.; van Rossom, S.; Desloovere, K.; Molenaers, G.; Huenaerts, C.; De Groote, F.; Jonkers, I. Pre-treatment EMG can be used to model post-treatment muscle coordination during walking in children with cerebral palsy. PLoS ONE 2020, 15, e0228851. [CrossRef]

146. Rabbi, M.F.; Pizzolato, C.; Lloyd, D.G.; Carty, C.P.; Devaprakash, D.; Diamond, L.E. Non-negative matrix factorisation is the most appropriate method for extraction of muscle synergies in walking and running. Sci. Rep. 2020, 10, 8266. [CrossRef]

147. Ivanenko, Y.P.; Poppele, R.E.; Lacquaniti, F. Five basic muscle activation patterns account for muscle activity during human locomotion. J. Physiol. 2004, 556, 267-282. [CrossRef] [PubMed]

148. Clark, D.J.; Ting, L.H.; Zajac, F.E.; Neptune, R.R.; Kautz, S.A. Merging of healthy motor modules predicts reduced locomotor performance and muscle coordination complexity post-stroke. J. Neurophysiol. 2010, 103, 844-857. [CrossRef]

149. Torres-Oviedo, G.; Ting, L.H. Muscle Synergies Characterizing Human Postural Responses. J. Neurophysiol. 2007, 98, 2144-2156. [CrossRef]

150. Reinbolt, J.A.; Haftka, R.T.; Chmielewski, T.L.; Fregly, B.J. Are patient-specific joint and inertial parameters necessary for accurate inverse dynamics analyses of gait? IEEE Trans. Biomed. Eng. 2007, 54, 782-793. [CrossRef]

151. Lerner, Z.F.; Demers, M.S.; Delp, S.L.; Browning, R.C. How tibiofemoral alignment and contact locations affect predictions of medial and lateral tibiofemoral contact forces. J. Biomech. 2015, 48, 644-650. [CrossRef] [PubMed] 
152. Ackland, D.C.; Lin, Y.-C.; Pandy, M.G. Sensitivity of model predictions of muscle function to changes in moment arms and muscle-tendon properties: A Monte-Carlo analysis. J. Biomech. 2012, 45, 1463-1471. [CrossRef] [PubMed]

153. Cleather, D.J.; Bull, A.M.J. Knee and hip joint forces-Sensitivity to the degrees of freedom classification at the knee. Proc. Inst. Mech. Eng. Part. H J. Eng. Med. 2011, 225, 621-626. [CrossRef]

Publisher's Note: MDPI stays neutral with regard to jurisdictional claims in published maps and institutional affiliations.

(C) 2020 by the authors. Licensee MDPI, Basel, Switzerland. This article is an open access article distributed under the terms and conditions of the Creative Commons Attribution (CC BY) license (http://creativecommons.org/licenses/by/4.0/). 